\section{Harm Reduction Treatment Interventions for Rural Methamphetamine Abuse}

\section{Abstract}

Rural methamphetamine abuse has reached epidemic levels. Methamphetamine causes detrimental consequences to its users such as severe psychological distress, socioeconomic hardship, physical health issues, legal problems and even prison time. Because rural areas have less access to treatment and other preventative methods, more effective solutions should be introduced to help make methamphetamine abuse a more manageable disorder. The primary focus of this article is to review existing approaches and suggest some innovative evidence-based harm reduction treatment and preventative education methods to individuals who abuse methamphetamine.

Keywords: Methamphetamine; Rural; Harm reduction; Treatment

\section{Bryan O Gere ${ }^{1 *}$ and Ashley Blessing ${ }^{2}$}

\author{
1 Alabama A\&M University, Normal, \\ AL, USA \\ 2 Arthur Center Community Health, \\ Mexico
}

*Corresponding author: Bryan O Gere

bryan.gere@aamu.edu

Ph.D. CRC, Alabama A\&M University, Normal, AL, USA.

Tel: (256) 372-5000

Citation: Gere BO, Blessing A (2017) Harm Reduction Treatment Interventions for Rural Methamphetamine Abuse. J Drug Abuse. Vol. 3 No. 3:17
Received: September 07, 2017; Accepted: September 21, 2017; Published: September 28, 2017

\section{Introduction}

During Methamphetamine (Meth) is the most common synthesized drug in the United States since the 1970's and can be proven by the thousands of clandestine "country" labs that have since been discovered [1]. A clandestine laboratory is defined as a place where preparation of illegal substances explosives and even biological weapons takes place [2]. Since 1997, meth has been the most prevalent clandestinely produced controlled substance in the United States [3].The drug has gained popularity for the effects that are elicited during use. People experience euphoria, enhancement of concentration, weight loss, a decreased need for sleep, increased aggression, and other similar effects [4]. It is also said to raise dopamine levels by 600 times higher than normal levels, causing a chemical rush [5].

Researchers show structural changes from meth use in the limbic regions of the brain, which are responsible for feelings and can even affect the hippocampus, which is responsible for new memories [6]. Long-term use of meth results in depletion of serotonin, due to its negative effect on tyrosine hydroxylase, the rate-limiting enzyme for serotonin production [3]. Long-term effects also include depression, paranoia, psychosis, anxiety, aggression and issues with feeling euphoria and/or pleasure because of decreased levels of dopamine and chemical changes in the brain [7].

Illicit substances such as meth have historically been used to achieve extreme euphoria and increased levels of dopamine in the brain, otherwise known as a "high" [8]. However, use of meth leads to addictive behaviors medical issues, mental disorders, crime, financial problems and spread of infectious diseases [9]. Initially, many illicit drugs were found in large cities, but over time, these substances have made their way to rural areas. In recent years, rural America has been hit very hard with an increase in the number of persons with substance abuse cases [10]. In fact, rural substance abuse has become equivalent or even surpassed urban substance abuse. Sadly, the hardest hit areas are those with few resources, funding and treatment facilities [11]. Meth is the most popular drug in rural areas due to ease of access of materials required for manufacture $[3,10]$. Because of the dangerous amounts of people abusing meth, the rural users are becoming a primary population for concern.

Many rural dwellers addicted to meth begin using when they are young and are typically influenced by others. A research study conducted by Bowen et al. [12] found that rural populations use meth for the first time to initiate peer-bonding, self-medication and out of curiosity. The authors also found that if a parent is using meth, their child is more likely to use the drug it with them for the first time. As use continues, tolerance is increased [13]. Tolerance is defined as an increase in the amount of a substance it takes to make an effect after an extended period of use [2]. With increased tolerance comes abuse and possible dependence. 


\section{Rural Methamphetamine Production and Abuse}

Small scale production of Meth in rural areas of the U.S. began in the 1990s. Due to the availability of necessary materials, clandestine laboratories are increasing in rural America. For every pound of meth produced from a clandestine laboratory, six pounds of waste is produced [14].This waste creates serious environmental problems. Tompkins-Dobbs and Schiefelbein [5] stated that to completely clean a location previously used in meth manufacturing, all children's toys, carpet, furniture, walls, curtains, bedspreads, and air vents have to be cleaned or disposed of because of the dangerous toxins produced. For a facility to be correctly cleaned, all absorbent materials such as carpets and clothes should be destroyed. Wallboard, floor coverings and counters should be removed and replaced; ventilation systems should be cleaned thoroughly and all filters within the home should be changed. The plumbing in the sinks, drains and toilets should also be removed and the septic tank needs to be inspected by the health department. The approximate cost for law enforcement to "clean up" methamphetamine labs that are seized ranges from $\$ 25,000-\$ 40,000$ [5]. This is because some labs are very toxic with chemicals and professionals may have to be called to take care of the cleaning.

Additionally, rural meth production also creates health and social problems. For instance, exposure to the toxic chemicals from meth labs can cause severe intoxication, disorientation, respiratory problems, chemical burns and damage to internal organs [3]. More importantly, tolerance for meth can develop with chronic use leading to dependence and abuse. Individuals with prolonged meth use also develop an inflammation of the heart lining [2]. Psychotic symptoms are also common with meth use and this can persist for months or years even after the individual has discontinued use of meth. Fetal exposure to meth is also prevalent leading to an increase in premature births and congenital deformities. Meth use has also been associated with social problems such as increase in domestic violence, robberies, rape and violence in rural areas [11].

In 2012, the second most abused drug in the world was Amphetamine-Type Stimulants, of which meth was reported to be the most used [15]. Meth runs an especially high risk of abuse and even dependence, which makes it dangerous to those who choose to experiment with it [16]. Rural populations do not have treatment options available for meth abuse like urban settings [17]. Simons et al. [8] suggested that $32 \%$ of substance abuse treatment admissions among 18-25 year olds are in rural counties and $26 \%$ are among urban counties [2].

\section{Current Rural Intervention Methods}

\section{2-step programs}

The twelve-step approach utilizes steps was created by Alcoholics Anonymous [18].The twelve steps are: (1) admittance of powerless over drugs - that abusers' lives have become unmanageable, (2) belief in a higher power to restore abuser to sanity, (3) submitting the will and lives to God as we understood him, (4.) make a searching and fearless moral inventory of ourselves, (5) admit to God, self and to others the exact nature of wrong doings, (6) be willing for God remove all defects of character, (7) humbly ask God to remove shortcomings, (8), make amends with persons that have been hurt as a result of the abuse, (9), make direct amends to such people wherever possible, except when to do so would injure them or others, (10) promptly admit wrongs, (11) seek to improve conscious contact with God, as we understand Him, through prayer and meditation and (12) have a spiritual awakening as the result of these steps and to practice these principles in all our affairs [18]. Many individuals use this method to work through the guilt their addiction has brought them. The focus is to "give your troubles to God and ask for forgiveness for your sins", which is a motivator for individuals who have high spiritual/religious needs.

\section{Punitive measures}

Research indicates nearly one third of individuals on probation are serving due to a drug offense and $15 \%$ are on probation for an alcohol-related driving offense. Using substances or being arrested for a drug-related offense significantly increases recidivism rates. Individuals on probation were found to be twice as likely to use illicit substances [17]. This is likely because individuals who are released from prison and/or jail have a more difficult time transitioning back into society with stigma behind their offense, difficulty meeting their needs due to availability, and peer pressure from their previous social crowd. Rural treatment facility admissions are more likely to have been mandated than voluntary self-admittance [11]. The stigma that follows posttreatment can be overwhelming and traumatic, unfortunately, and due to the lack of population density, frequently rumors and gossip spread about the individual and they ultimately feel ostracized from their community. However, rehabilitation-based treatment for offenders is proven to reduce recidivism and is evident to help individuals transition back into society with less stress and factors against their recovery.

\section{Drug abuse resistance education (D.A.R.E.)}

Drug Abuse Resistance Education (also known as D.A.R.E.) was a program facilitated in some grade schools to help educate adolescents about the dangers of drug use and how to say no [19]. It should be noted that D.A.R.E. curriculum was aimed at individuals who were in the last year of middle school, which is earlier in age than the average first age of use. D.A.R.E. was created as a response to Nancy Reagan's "Just Say No" campaign to combat the war on drugs. D.A.R.E. is taught by trained law enforcement and is meant to teach drug abuse resistance education, exactly what the acronym states. The curriculum includes 17 lessons, each lasting $45 \mathrm{~min}$ to $1 \mathrm{~h}$ at 1 week intervals, intended to teach students how to recognize and resist to social pressures to resist drugs [19].

D.A.R.E. has been shown to be effective in the short term in children in their late adolescents, but has not shown long-term effectiveness for individuals when compared to a control (a group of students who did not receive D.A.R.E. or who received another interactive prevention/education program) [19]. The 
program has also been effective for changing the adolescent's personal opinions of drug use to a less negative perspective, but has not influenced drug use habits. When participants were asked about what was learned, individuals recall the officers showing them every ingredient to make methamphetamine and how to manufacture it and just saying no [19].

\section{The matrix model}

The Matrix model was developed in response to the 1980's stimulant abuse surge; as individuals went to seek treatment, they were not seeing positive results. Because of a lack of capacity to treat in 28 day hospitals and mental health clinics, clinicians decided to implement the Matrix model [20]. The Matrix model incorporates evidence-based practices to effectively help individuals struggling with dependence issues to begin alleviating those issues with acquired skills. Components of the program include individual sessions, early recovery groups, relapse prevention groups, family education sessions, 12 step meetings, social support groups, relapse analysis and urinalysis [20].

\section{Faces of meth}

Faces of Meth takes mug shots of individuals who have been arrested for methamphetamine related crimes comparing a "before" image of an individual who began to use methamphetamine and "after" image from a later arrest. The negative effects shown are "meth mouth" (rotting of the teeth), scabs on the face and body, significant weight loss and obviously criminal behaviors. Faces of Meth did not show to be effective due to the ambiguity of what other substances the user has used, the situation/location in which the user indulged in methamphetamine and the "scare tactic" is just not an effective method for most individuals who would seek to use meth. It has been shown that users look for thrill-seeking activities and to get a "rush.

\section{The Montana meth project}

The Montana Meth Project (MMP) focused on using education to combat and prevent meth use [21]. This campaign utilized an abrasive, confrontational graphic method as the central component and primary method for deterrence. Users are portrayed as unhygienic, dangerous, untrustworthy, and exploitative by threatening to kill their parents, being raped, and prostituting themselves to fund their habit. These intense graphic portraits are shown on televisions, billboards and announced on the radio [22]. The MMP claims this method is evidence-based and realistic as a deterrent for methamphetamine use. These advertisements are seen by teens, on average, three to five times a week.

According to $\mathrm{MMP}$, the advertisements have caused dramatic shifts in the perception of risks associated with meth use, more frequent parent-child communications, greater social disapproval and significant declines in meth use and associated crime. When further studies confirmed the effectiveness of MMP, federal funding was approved for the program and many other funding sources also supported the program [21]. However, other studies are not so convinced about the effectiveness of MMP
[22]. Although the idea behind the ads is excellent, enthusiastic approach to prevention of meth use using scare tactics does not prove to be an effective preventative method.

\section{Harm Reduction Treatment Interventions}

Providing harm-minimizing based services to individuals with abuse/dependence issues is a more efficient method of treatment. Harm reduction (HR) is a method of counseling and intervention services that was created in response to the HIV/AIDS epidemic [23]. Harm reduction focuses on exactly what it states, reducing harm to the individual and their lives without having to promote abstinence as the only [24]. Harm reduction utilizes the five stages of change: pre-contemplation, contemplation, preparation, action, and maintenance [23]. HR was created so that individuals who want to seek services can possibly do so without having to immediately promise abstinence or without forcing immediate abstinence (i.e., being arrested).

To be able to utilize harm reduction, MacMaster et al. [23] proposed five essentials that counselors should be aware of: (1) substance use has and will be part of our world; accepting this reality leads to focus on reducing drug related harm rather than reducing drug use, (2) abstinence from substances is clearly effective at reducing substance related harm, but is only one of many possible objectives of services to substance users, (3) substance use inherently causes harm; however, many of the most harmful consequences of substance use (HIV/AIDS, Hepatitis $C$, overdoses, etc.) can be eliminated without complete abstinence, (4) services to substance users must be relevant and user friendly if they are to be effective in helping people minimize their substance-related harm, and (5) substance use must be understood from a broad perspective and not solely as an individual act; accepting this idea moves interventions from coercion and criminal justice to a public health or counseling perspective. It is imperative that practitioners and policy makers understand what harm reduction truly is - a means to reduce harm in a regulated manner.

Haden [25] has introduced 7 principles that counselors and policy-makers should take into consideration when it comes to harm reduction: (1) the goal is to reduce harm - practitioners and policy makers should take into consideration that with current policies, harm is not being reduced, therefore it is not an effective policy, (2) social capital needs to be increased - put simply, relationships hold value. Those with abundant social networks and receive the reciprocity that flow from them are happier, healthier and wealthier. The opposite is true as well; those with fewer social networks and environmental supports struggle more. It has been proven by many studies that adolescents with stronger connections to school, family and the community are less likely to use alcohol, tobacco and marijuana. It is important to increase strong and supportive bonds to help reduce and eliminate risky behaviors; (3) the culture of drug use needs to be understood and influenced - drug use patterns for different populations should be studied to understand the reasons behind use, the effect of use on socioeconomic status, etc. [25]. 
For the most effective intervention, practitioners and policy makers would have to engage the drug use community in developing a new drug using culture that works actively to reduce harms, (4) the goal is to use the least restrictive intervention - the principle of "least restrictiveness" states that each drug should be controlled using methods that are minimally restrictive as possible, given that the goal is to achieve specific health and social outcomes. Both are human rights and economic justifications which give an excellent reason to pursue these methods, (5) prevention and treatment are vital - only after prohibitionism over drugs will these be able to flourish. Many feels discriminated or persecuted when they seek medical and treatment interventions [25]. There are at least two reasons why this is true - prohibitionism impairs the development of honest, factual prevention programs and alienated drug users, which causes serious health and social consequences. It is important to gain insight and experience before a clear relationship can be built to begin mending the corrupted prohibitionist model, (6) learn the lessons from alcohol and tobacco - reflect on the prohibition of alcohol and tobacco and how those both ended in regulation and (7) changes need to occur incrementally - it would be very difficult to make quick, drastic changes to the current policies. It would be beneficial to make the changes occur over a long period of time to help citizens adapt and understand the new policies.

The biggest benefit of harm reduction for practitioners is that it provides a compassionate and practical method of treatment. Practitioners who practice in a community health setting look to provide: a) low threshold access to desired services and other practical supports that are not contingent on changing drug use behaviors; b) unconditional support and motivational strategies designed to engage people in moving toward the development of healthier behaviors; c) education and practical guidance to reduce harm and enhance recovery [24].This is more accepting for individuals who need mental health care or substance abuse counseling, but who have substance use disorders and are ashamed to seek help.

\section{Implementing Community Harm Reduction Programs for Meth Abusers}

Harm reduction methods should be taught to prevent bloodborne diseases such as HIV/AIDS and Hepatitis C. Needle exchange programs should be established to give individuals an opportunity to practice safer use (without the indication that it is legal for methamphetamine use and to "shoot-up" with needles). Some of the reasoning behind wanting to provide needle exchange programs is that it provides clean needles to users with the only requirement that they must bring back the used needles that they had previously received. Only then are the users allowed to pick up more needles. This program does not have to be monumental in size, because not everyone shoots up meth, but would benefit citizens of the community because it lowers the risk of blood-borne diseases that can be spread by those who have already been infected or those who discard needles improperly. Being able to provide this service would lower the cost tax payers contribute to people being incarcerated in prison, which could be used for drug prevention, treatment, and maintenance programs that help individuals learn how to deal with and manage their addiction.

Along with needle exchange programs, other services and programs should be offered such as Meth Anonymous (MA) $[17,25]$.This would offer monumental support to the criminal offender and to individuals who find group support effective. Counseling services should be made available for those who would like to utilize them. Most state Medicaid programs pay for community mental health counseling and inpatient psychiatric hospitalizations. The fees that are not covered by Medicaid could be paid from grants received from NIDA, SAMHSA, and other government agencies for individuals who do not meet minimum income requirements. Another payment method is to consider sliding fees based on income. Lastly, clinicians and healthcare professionals should teach information regarding harm reduction to patients and clients. Literature and digital media should be made available for individuals who are looking for information on how to quit using and when they seek the treatment, it is imperative that they are not punished by law enforcement for being in possession or using methamphetamine. If there are punitive measures for active users seeking help, it is almost guaranteed that the individuals will not utilize the services.

\section{Utilizing empty gel capsules as a method of harm reduction}

Another effective method of harm reduction is distribution of empty capsules that the consumer can place their dose of methamphetamine in. The user would come into a community clinic that also offers counseling and peer recovery advocates. The advocates would show the individual how to use the capsule - everything from opening the capsule and placing the user's dose - to teaching the user the reason that capsules are a safer method.

Using gel caps can be a proven cost-effective measure as large quantity are available for purchase on the internet or through pharmacies for approximately $\$ 40$ for 1,000 empty capsules [26].This method has been tested in the Czech Republic by questionnaire assessing how they use the gel capsules as a method of harm reduction and how popular the method has become in treatment practice. The target populations consisted of primarily intravenous methamphetamine users whose veins have been damaged and users that wanted to quit injecting methamphetamine. The perceived benefits of the capsules included ease of use and distribution and satisfied the oral fixation aspect of methamphetamine use.

The only perceived drawback was regarding oral health. However, it was discovered that continual ingestion per this method could cause extensive stomach damage, but as most methods of harm reduction; this is not meant to be an end-all to the physiological side effects of ingesting methamphetamine [26].This has proven to be effective in the Czech Republic as a method of harm reduction that could potentially be beneficial for the United States, especially in rural America, where resources are very limited and socioeconomic gaps are more apparent. 


\section{Stimulant maintenance}

Prescribing individuals who are addicted to methamphetamine stimulants may be an effective method of harm reduction. Similar to methadone maintenance, stimulant maintenance is the act of distributing a legally, laboratory-produced prescription stimulant such as Adderall or Ritalin to help users titrate their methamphetamine tolerance at their convenience, with a treatment plan goal of abstinence eventually.

Maintenance programs have been shown to be successful in helping individuals work through cravings for their preferred drug. Studies prove that methadone maintenance therapy for opioid addiction has robust outcomes in keeping individuals from drug seeking, committing crimes for drugs and searching for opioids in prisons [27].This method can be enacted similarly to methadone maintenance therapy; the user goes through specific levels of treatment to be able to eventually take-home doses and avoid daily facility dosing visits.

\section{Harm reduction information for sexual intercourse}

In addition to harm reduction by replacing needles, many individuals should also be taught harm reduction methods for sexual intercourse including low-cost (possibly free) HIV/AIDS testing and how to conduct less risky sexual behaviors. Funding should be accessible to high risk individuals. When individuals receive funding, it could potentially lower the cost of Medicare claims, which is utilized by many who are considered "in poverty" or who have no or low incomes. Research conducted by Zule et al. [28] has shown that men who have sex with men (MSM) make up only approximately $2 \%$ of the United States population, but they account for over $50 \%$ of new HIV infections each year. Meth use has been contributed to this rise of infections in men who have sex with men (MSM) because of the increased sexual drive, the lack of inhibition, decreased condom use [28]. Meth use in MSM also contributes to multiple sexual partners, group sex, more extreme sexual behaviors, such as "fisting" and even condom breakage [28].

\section{Implementing/Maintaining Harm Reduction in Counseling}

Zule et al. [28] discovered that participants were influenced by a single session of motivational interviewing, to decrease risky sexual behaviors and meth use. Other studies showed that a brief client-centered intervention is just as effective as multisession theory-based interventions [10]. If this is the case, a variety of counselors could be hired to talk to the people who have been arrested. A brief intervention is more effective than no intervention. Therefore, it would be extremely beneficial for offenders to receive some type of intervention upon booking at the jail and sobering up. This would also potentially lower the number of repeat offenders and would give offenders an opportunity to rejoin the community. Because of the heightened community involvement, offenders start to learn the morals of others and make friends outside of their normal group with whom they typically use. Positive community influences make a huge impact on their lives.

When trying to implement harm reduction in counseling, it may be good for the clinician to analyze different styles and integrate harm reduction into the counseling method that works best for the clinician. Some evidence-based practices will be presented and evaluated for the clarification of the reader. The National Institute on Drug Abuse's website suggests utilizing cognitive behavioral therapy, contingency management interventions; solution focused brief therapy/motivational interviewing, community reinforcement approach, the Matrix Model, 12-step facilitation therapy and/or family behavior therapy.

\section{Solution focused brief therapy/motivational interviewing}

Some choose to integrate harm reduction into solution-focused brief therapy. Solution-focused brief therapy (SFBT) is a style of counseling that is specifically meant to be brief ( $2-3$ sessions) and the sessions are focused on the solution to the issue the individual brings [29]. SFBT is an evidence-based practice that has proven to be effective, even for the brief interventions. Motivational interviewing follows a similar method to SFBT, it focuses on problem solving the issue at hand. Not much is said about drug use unless the individual is bringing that issue to the sessions. Harm reduction and solution-focused go together because of the concept that SFBT focuses on the positives and promotion of reducing harm during SFBT makes more sense because of how "laid-back" of a style it is. Individuals are not persecuted for their drug use and can problem solve by viewing other aspects of the issue as inspired by the counselor/therapist.

\section{Behavioral therapies}

Cognitive Behavioral Therapy (CBT) is an excellent evidencebased model to utilize with individuals who have addictions. CBT helps individuals learn to follow the $A B C$ model: "Activating event, personal Beliefs, Consequences of those thoughts" and challenge their thoughts, which is an evidence-based rational way. This helps individuals overcome many clinical problems ranging from phobias to depression to views of the world.

Dialectic Behavior Therapy (DBT) is an effective treatment model for individuals who have difficulty with regulating a chaotic lifestyle and their chaotic emotions, such as the individuals who have Borderline Personality Disorder. This helps individuals learn many skills such as mindfulness (which is finding one's personal 'equilibrium'), interpersonal effectiveness, distress tolerance and emotion regulation.

\section{Contingency management (Motivational incentives)}

Contingency Management (Motivational Incentives) is amongst the most empirically supported methods for supporting and increasing abstinence. Contingency management uses principles from operant conditioning such as regular monitoring of someone's drug use by urinalysis and delivery of an incentive only after drug abstinence has been verified. If the said incentive is a 
positive reinforcer, it competes with the reinforcing effects of the drug and increases the likelihood that drug abstinence is initiated and maintained [30].The reason this seems to be effective is that the benefits typically outweighs the benefits of using the drug. Therefore, this method could be utilized in sessions while utilizing the harm reduction approach. To utilize the harm reduction approach, decrease in drug use should be monitored by self-report, if there is a trusting relationship between the counselor and the client and the client understands there are no punishments if the client and uses. This should be considered part of the process of recovery and the road to abstinence.

\section{Community reinforcement approach}

Community Reinforcement Approach (CRA) is a comprehensive behavioral treatment package that focuses on the management of substance related behaviors and other disrupted life areas. The goal is to help people discover and adopt a pleasurable and healthy lifestyle that is more rewarding than a lifestyle filled with using drugs [31]. This proves to be effective because it offers a comprehensive treatment method that includes counseling and cognitive-behavioral changes to help shift the desire to get "high" to a more beneficial and healthy habit. It has been proven that enriching an individual's environment with non-substancerelated rewarding alternatives encourages them to reduce their substance use [31]. This is stating that allowing individuals to become "bored" or not engaged in pleasurable activities inspires and promotes drug use. This statement seems to directly relate to Contingency Management/Motivational Incentives by insisting that individuals who are rewarded for not using will be more inspired to reach towards abstinence. Introducing new stimuli to individuals helps distract them from their addiction, allowing it to become more manageable. However, because of desensitization, this method is not proven as an effective long-term method for substance abuse treatment.

Many different options and methods can be brought to counseling that inspire cognitive change, behavioral changes

\section{References}

1 Shukla RK, Crump JL, Chrisco ES (2012) An evolving problem: Methamphetamine production and trafficking in the United States. Int J Drug Policy 23: 426-435.

2 Garriott W (2010) Targeting the local: Policing clandestine methamphetamine production in a rural US community. Canadienne Droit Et Societe 25: 1-19.

3 Gregg J (2012) Rural adolescent substance abuse: Prevention implications from the evidence. J Rural Nurs Health Care 12: 41-50.

4 Sexton R, Carlson R, Leukefeld C, Booth B (2009) An ethnographic exploration of self-reported violence among rural methamphetamine users. J Ethn Subst Abuse 8: 35-53.

5 Tompkins-Dobbs K, Schiefelbein J (2011) Emergency department policies and procedures for treatment of patients abusing methamphetamine. J Emerg Nurs 37: 437-443.

6 Rusyniak DE (2013) Neurological manifestations of chronic methamphetamine abuse. Psychiatr Clin N Am 29: 641-655. and goal discovery. Solution focused brief therapy/motivational interviewing is an effective evidence-based practice for brief contact with individuals (1-2 sessions) focusing on problemsolving and becoming goal oriented; cognitive behavioral therapy is an evidence based practice that helps individuals challenge, rationalize, and change their thoughts; dialectic behavioral therapy helps individuals learn and accept that the world is what it is, no more, no less; contingency management (motivational incentives) focuses on giving individuals prizes or incentives for extended periods of abstinence or decreased use; and the community reinforcement approach works towards providing stimulating, healthy activities in the environment to give the individual something other to do than drugs. Providing these distraction methods is an effective method because it is imperative that individuals change their environment and views about drug use; these methods help stimulate a change in their habits by breaking the monotony of their environment.

\section{Conclusion}

Methamphetamine use in the United States has slowly taken over the Midwest making the abnormal use seem like a "rural epidemic." Clandestine laboratories in the rural Midwest have been devastating to small communities because of both the cost of cleanup and the loss in of lives in the community. Harm reduction is a treatment method that does not ask for immediate abstinence, but aims to reduce harm in the user's life. This approach can be more effective in meth treatment because it does not make someone quit right away when he or she is just curious and wants to gather information. Harm reduction has multiple aspects such as low-cost treatment availability, maintenance programs, and needle exchange programs. It is also important to teach individuals who partake in risky sexual behavior methods of safe sex. It is recommended that clinicians consider harm reduction as a treatment method when trying to work with individuals who abuse meth.

7 Grant K, Kelley S, Agrawal S, Meza J, Meyer J, et al. (2007) Methamphetamine use in rural Midwesterners. Am J Addict 16: 79-84.

8 Simons JS, Dvorak RD, Batien BD (2008) Methamphetamine use in a rural college population: Associations with marijuana use, sensitivity to punishment and sensitivity to reward. Psychol Addict Behav 22 444-44

9 Swendsen J, Burstein M, Case B, Conway KP, Dierker L, et al. (2012) Use and abuse of alcohol and illicit drugs in US adolescents: Results of the National Comorbidity Survey-Adolescent Supplement. Arch Gen Psychiatry 69: 390-398.

10 Lambert D, Gale J, Hartley D (2008) Substance abuse by youth and young adults in rural America. J Rural Health 24: 221.

11 Roussell A, Holmes M, Anderson-Sprecher R (2009) Community characteristics and methamphetamine use in a rural state: An analysis of pre-incarceration usage by prison inmates. Crime Delinq 59: 1036-1063.

12 Bowen A, Moring J, Williams M, Hopper G, Daniel C (2012) An investigation of bio-ecological influences associated with first use of methamphetamine in a rural state. J Rural Health 28: 286-295. 
13 Bartlet R, Brown L, Shattell M, Wright T, Lewallen L (2013) Harm reduction: Compassionate care of persons with addictions. Medsurg Nurs 22: 349-358.

14 Vearrier D, Greenberg MI, Miller SN, Okaneku JT, Haggerty DA (2012) Methamphetamine: History, pathophysiology, adverse health effects, current trends and hazards associated with the clandestine manufacture of meth. Disease-a-Month.

15 Courtney K, Ray L (2014) Methamphetamine: An update on epidemiology, pharmacology, clinical phenomenology and treatment literature. J Alcohol Drug Depend 143: 11-21.

16 Armstrong EG (2007) Moral panic over meth. Contemporary Justice Review 10: 427-442.

17 Oser C, Harp K, O'Connell D, Martin S, Leukefeld C (2012) Correlates of participation in peer recovery support groups as well as voluntary and mandated substance abuse treatment among rural and urban probationers. J Subst Abuse Treatment 42: 95-101.

18 Alcoholics Anonymous ("Big Book," 4th ed.) (2001) New York: AA World Services, Inc.

19 Pan B (2009) A multivariate approach to a meta-analytic review of the effectiveness of the DARE program. Int J Environ Res Public Health 6: 267-277.

20 Herbeck DM, Hser YI, Teruya C (2008) Empirically supported substance abuse treatment approaches: A survey of treatment providers' perspectives and practices. Addict Behav 33: 699-712.

21 Erceg-Hurn D (2008) Drugs, money and graphic ads: A critical review of the Montana meth project. Prev Sci 9: 4 .

22 Anderson D, Elsea D (2014) The Meth Project and teen meth use: New estimates from the national and state youth risk behavior surveys. Health Economics.
23 MacMaster SA, Tripp K, Argo S (2008) Perceptions of HIV risk behaviors and service needs among methamphetamine users in rural Appalachian Tennessee. J Ethn Subst Abuse 7: 115-130.

24 Mancini MA, Wyrich-Waugh W (2013) Consumer and practitioner perceptions of the harm reduction approach in a community mental health setting. Community Ment Health J 49: 14-24.

25 Haden M (2008) Controlling illegal stimulants: A regulated market model. Harm Reduct J 5: 1 .

26 Mravčík V, Škařupová K, Orlíková B, Zábranský T, Karachaliou K, et al. (2010) Use of gelatine capsules for application of methamphetamine: A new harm reduction approach. Int J Drug Policy 22: 172-173.

27 Johansson BA, Berglund M, Lindgren A (2007) Efficacy of maintenance treatment with methadone for opioid dependence: $A$ meta-analytical study. Nord J Psychiatry 61: 288-295.

28 Zule WA, Poulton WE, Coomes CM, Mansergh G, Charania M, et al. (2012) Results of a pilot study to reduce methamphetamine use and sexual risk behaviors among methamphetamine-using men who have sex with men (MSM) not currently in treatment. J Psychoactive Drugs 44: 351-358.

29 Brent D, McMakin D, Kennard B, Goldstein T, Mayes T (2013) Clinical review: Protecting adolescents from self-harm: A critical review of intervention studies. J Am Acad Child Adolesc Psychiatry 52: 12601271.

30 Benishek LA, Dugosh KL, Kirby KC, Matejkowski J, Clements NT, et al. (2014) Prize-based contingency management for the treatment of substance abusers: A meta-analysis. Addict 109: 1426-1436.

31 Meyers R, Roozen H, Smith J (2011) The community reinforcement approach: An update of the evidence. Alcohol Res Health 33: 380. 